\title{
The Definition of The Psychological Pressure on Children by The Parents at The Post-Divorce Stage
}

\author{
Arkadi Aghvan Mehrabyan \\ Psychological center "Zhesture”, Yerevan, Armenia
}

\begin{abstract}
ARTICLE INFO
Keywords:

Psychological Pressure

Child

Divorce

Emotional Violence

ABSTRACT

In this article we have tried to present our research in this field, drawing on a parallel with world experience, research and obtained data.

It is well known that the innate desire to have a relationship with parents is one of the most powerful instincts of man, perhaps surpassed only by the instinct of survival and the instinct of protection own children. Among normal children, this instinct is rarely suppressed if there is no stimulating influence.

In our article we have tried to show that alienation is more widespread and depressing for children and parents than previously thought. It is more important to raise this issue these days because it may seem strange that all over the world, every day, every hour, is expressing their views on the protection of children's rights, many laws and international conventions are being adopted, but the children still remain the vulnerable and defenseless ring.

A thorough study of the key elements of parent alienation in research literature has revealed that it contains elements of maltreatment with children. At the same time, our research has shown that the more a child persistently insists on not being in touch with the other parent, the greater the pressure on the child from the other parent. Therefore, parental alienation requires relevant measures for children protection.

A notorious factor should be the involvement and taking the responsibility of competent structures, rather than avoiding or ignoring such phenomena.
\end{abstract}

\section{Introduction}

The number of divorces has increased significantly in recent years. But what is most disturbing, is the increased use of psychological violence against children by one or another parent (mainly the one who cares about the child) who either takes revenge on the other parent, has material expectations or other motives.

The field of parent alienation is full of contradiction, especially as to whether there are parental forms of child abuse and domestic violence. These are issues related to abuse, rejection and alienation, as well as legal reforms and medical interventions needed to struggle against alienation, and should be found not only by researchers but also by practitioners, psychologists, social workers, educators, and why not also for law enforcement agencies and politicians in general.

There are many different views on the current state of alienation research. An analysis of parental alienation studies over the past decade shows that this syndrome is more widespread and depressing for children and parents than previously thought. We have also begun to study the consequences that a parent's alienation can have on a child's mental and physical health.

\footnotetext{
* Corresponding author E-mail address: mehrabyanarkadi@gmail.com 
A new scientific consensus is already emerging about the definition and prevalence of alienation from parents, and its negative consequences for parents and children.

For example, parental alienation is recognized as a manifestation of three disorders identified in the DSM-V (American Psychiatric Association, 2013): "Parent-Child Relational Problem," "Child Affected by Parental Relationship Distress," and "Child Psychological Abuse." Parental alienation is related to two symptom clusters identified in the DSM: "impaired functioning in behavioral, cognitive, or affective domains" and "negative attributions of the other's intentions, hostility toward or scapegoating of the other, and unwarranted feelings of estrangement" on the child's part of the child. The current draft of the World Health Organization's International Classification of Diseases also contains a specific definition of parental alienation.

Moreover, the study of many aspects of parental alienation is far more convincing than is often assumed. Recent quantitative research raises serious concerns. In clinical and research literature there is also an agreement on the main components of alienation (Clemente, M., \& Padilla-Racero, D. 2015)

We believe that more research needs to be done with parents on interventions and strategies at their individual, family and group levels. The last base is enforcement; perhaps the most discussed area of intervention, as law enforcement agencies can take under detention and imprisonment, or appoint family therapy orchoose non-intervention in the situation. There are very few studies of methods of communicating with parents while alienation of the children, despite court orders. We believe that therapeutic interventions will be more effective when strict legal sanctions are applied to disregard general parenting guidelines.

\section{The Emotional and Psychological Attachment of Children with Parents}

It has long been an axiom that parents are the immediate and mediating agents of all the needs of the child (especially in babyhood and early childhood), and the attachment of children to them is both geneticand acquired from the first day of life (TitarenkoV.Ja, 1987). If mother's care provides development of emotional field, tenderness, kindness, creativity, then the father is the source of efficiency and power (Dumitrashku T.A., 1991).

The Attachment theory was developed by psychiatrist and psychoanalyst John Bowlby: Due to this theory, he explained how mother-child relationships influence on child's future life. (Boulbi D.Zh., 1988).

Different types of parent-child attachment disorder have a significant impact on the child's future development, in the relationships with the outside world, and provide the formation of the attachments with friends, other people, opposite sex and teachers.

At an early age, children who have been separated from their parents for a long time may develop a refusal to communicate with them and would have negative emotions in the case of attempts of caring.

It is believed that in the first years of life, the child and mother's secure attachment is the base ofthe future sense of confidence and security in the surrounding world (Smirnova E.O., 1995) The children who have secure attachment with their mother during 12-18 months, they are quite communicative at the age of two, express their judgement during games. As a teenager, they are more interesting as a business partners than the children with insecure attachments. At the same time, the children whose primary attachment is characterized by "disorganization" and "disorientation" have a risk of aggressive behavior and peer rejectionat a pre-school age.

Children who have secure attachment with their mother when they are 15-month-old, at the age of 3.5 show vividly expressed leadership traits at their peer group. They initiate gameseasily, are very concerned about the needs and feelings of other children, and are generally well known among children. They are curious, independent and energetic. On the 
contrary, children who have had an insecure attachment with their mother for 15 months express a kind of social inactivity in the kindergarten, and reluctance to engage in other children's play activities. They are less curious and have inconsistent goals.

The father is considered to be the one of the main characters in the child's life. He has a great contribution to the upbringing of the child, the development of their abilities, the acquisition of various skills. The father, in its great importance, is irreplaceable to the child. The child gains and strengthens the strong qualities from the father.

One of the important conditions that ensures the father's influence on the child and their future interdependence, is considered their communication as early as possible. The first 2-3 days after their birth can be decisive when the baby's brain is impressed with the first traces of external events. In addition, it has been revealed that except for breastfeeding, fathers are able to provide all the care they need. Fathers are able to grasp the signals of children as clearly as mothers, and newborns can communicate with their father no less than mothers. Fathers who devote a great deal of time to the care of breastfeeding children state firm relationships of attachment, which benefit their children greatly (Avdeeva N., 2005). Fathers who hold the newborn immediately after the birth are also likely to continue to play with and care for their adult children. It is a new role of a caring father that has a positive impact on the child's psychological development. Newborns whose fathers have been actively involved in their upbringing have scored high in the tests of motor and mental development. So they grow socially more responsible (Jejnsvort M. D., 1979)

G. Craig (2002) observes that fathers who have a strong emotional bond with breastfeeding children are more sensitive to their children's changing needs and interests. Such fathers have a great influence on their children, which often obey them and want to imitate them because of the close relationship between them (Krajg G., 2000).

\section{Parental Alienation}

Parental alienation, which most often occurs during or after parental separation in the context of child guardianship disputes, includes "Planning a child by one of the parents" to blame, hurt, and harm the relationship between the child and the targeted parent (or even completely eliminate) the other. As a result, the targeted parent is defeated, and their reputation as a parent who is worthy of the child's love and attention is ruined (Harman, J. J., Kruk, E., \& Hines, D. A. 2018) Such defamation results in the emotional rejection of the child by the targeted parent and the loss of a loving parent in the child's life. Parental alienation is manifested in illogical, non-existent, or exaggerated reasons for the child's unwillingness or refusal to have a relationship with the parent. Parental alienation differs from parental rejection, which involves behavior when the parent himself or herself damages the relationship with the child, usually due to the parent's own shortcomings. Parental alienation ranges from mild, subtle forms to more serious forms of aggression and compulsory control, leading to the child's complete refusal to interact with the targeted parent. There are no gender differences in who is guilty and who the target of parental alienation is. However, if a child spends most of their time with only one parent, this is a strong sign of who can remove the child from the other parent (Baker, A. J. L. \&Eichler, A. 2016).

The field of parent alienation is full of contradiction, especially as to whether there are parental forms of child abuse and domestic violence. There are many different views on the current state of alienation research. An analysis of parental alienation studies over the past decade shows that this syndrome is more widespread and exhausting for children and parents than previously thought. Although for those who doubt their concepts, new scientific consensus is emerging about the definition and prevalence of alienation for parents and its consequences for parents and children. There is a general agreement that parental alienation is a form of emotional abuse of children. It is commonly accepted that parental alienation is 
usually associated with the experience of a child who, under the influence of one parent, rejects and begins to hate the other parent, as well as with the behavior of the parent who is poisoning the child's relationship with the other parent.

Alienation of parents is described as a "form of children's programming". Unjustified campaign of defamation against the targeted parent, which leads to child's unintentional abandonment of the parent (Bernet, W., \& Baker, A. 2013).

In the case of parents' alienation, the attitude of the children towards the alienated parent is almost alwaysabsolutely negative, the parent is being considered evil and, in extreme cases, completely forgotten. For a child, parent alienation is a serious psychological condition based on the false belief that the alienated parent is not worthy of being a parent.

There are, of course, exceptional cases where a child who has been subjected to harsh treatment or domestic violence for a long time justifiably fears and rejects the parent. However, they are very few cases, and there are numerous studies of child abuse that show that even children who are physically abused rarely reject the abusive parent as willingly as alienated children do. /Clawar, S. S., \&Rivlin, B. V. 2013/ Gottlieb summarizes the clinical picture of child protection:

"In spite of the torture and neglect experienced by the 3,000 adopted children who were under my care, these children rarely refused to communicate with their parents, even with outright cruel parents. On the contrary, the children tended to protect and cling to the cruel parent. Moreover, in the rare cases where children reject a parent, there has always been some evidence that programming is available (usually by foster parents who have the secret purpose of adopting a child)." (Gottlieb, L.J. 2012)

Thus, it is unnatural for a child to refuse a parent, even a violent abuser. When a specialist observes how a child resolutely rejects a parent in the absence of confirmed violence, neglect, or lack of parental skills, which should never be assumed solely based on the child's statements, one of the first considerations should be that the other parent is alienating (thealienating of the other parent from a child). Moreover, if a child rejects a parent, it should never be assumed that this parent must have done something to deserve it.

Twenty-four years after observing children subjected to violence, Edward Kruk has come to the conclusion that the innate desire to have a relationship with parents is one of the most powerful instincts of man, perhaps surpassed only by the instinct of survival and the instinct of protection own children. Among normal children, this instinct is rarely suppressed if there is no stimulating influence (Edward Kruk, 2018).

Identification of a child with a violent parent and parental protection of the child are evident in cases of parental alienation. The child will deal more closely with the alienating and cruel parent than reject them.

Knowledge of parental alienation indicates that parental alienation can be a serious form of child emotional abuse that is connected with both physical abuse and neglect. In terms of definitions, the two main elements of parental alienation (the serious mental state for the child that comes from the parent's alienating strategy), correspond to the two major components of child abuse. First of all, child abuse and parental alienation are serious damages and pose a serious threat to a child's well-being. Second, abuse is due to the human factor: it is the result of human actions. This can be a form of joint action by a parent or guardian and / or several people. For example, there are social, legal, political and economic factors that endanger the well-being of children. As a result of individual actions of the parent, parental alienation is considered as a form of abuse against children. As legal systems typically exclude one parent from their daily lives, parental alienation can also be viewed as a form of collective abuse. 
Parental alienation involves a series of abuse strategies by one parent aimed at encouraging the child to leave the other parent. In this way, children are subjected to one parent for rejecting the other.

As we have already mentioned, parenting alienation for a child is a serious mental disorder based on the false belief that the alienated parent is a dangerous and worthless parent.

The first defining characteristic of parental alienation, as a form of emotional abuse of children, is related to alienating behavior. It involves implementing a series of abusive strategies by the parent who has alienated to help the child reject the other parent. In order for the child to reject the other parent, they are manipulated by destroying and interfering the relationships between the child and the other parent. Such strategies include denying, conditioning, restricting communication, eliminating the other parent from the child's life and memory, forcing the child to reject the other parent, giving the impression that the other parent is dangerous, forcing the child to make a choice between parents, threatening to terminate the relationship, andreduction and restriction of the communication with the family of targeting parent. Emotional manipulation tactics, encouraging disobedience, concealing information, targeting defamation, etc. are also used. Such defamation results in the child emotionally rejecting the targeted parent and losing the caring and loving parent. Baker and Darnell outline seventeen parental alienation strategies (Baker and Darnell, 2006).

1. Badmouthing. The target parent is presented as unloving, unsafe and unavailable. Flaws are exaggerated or manufactured. Such statements are madefrequently, intensely, and with great sincerity.

2. Limiting contact: The target parent has few opportunities to counter the badmouthing message.

3. Interferingwith communication. Phones are not answered, e-mail messages are blocked, and messages are not forwarded.

4. Interfering with symbolic communication: Thinking about, talking about, and looking at pictures of a parent are prohibited. The alienating parent creates an environment in which the child does not feel free to engage in these activities. The child's mind and heart are preoccupied with the alienating parent and there is no room left for the child's thoughts and feelings about the target parent.

5. Withdrawal of love: What angers the alienating parent most is the child's love and affection for the target parent. Thus, the child must relinquish the love of the other. The child lives in fear of losing the alienating parent's love and approval.

6. Telling the child that the target parent is dangerous: Stories might be told about ways in which the target parent has tried to harm the child.

7. Forcing child to choose: The alienating parent will compel the child away from the target parent by scheduling competing activities and promising valued items and privileges.

8. Telling the child that the target parent does not love him or her: The alienating parent will foster the belief in the child that she is being rejected by the target parent and distort every situation to make it appear as if that is the case.

9. Confiding in the child: The alienating parent will involve the child in discussions about legal matters and share with the child personal and private information about the target parent. The alienating parent will portray him/himself as the victim of the target parent, inducing the child to feel pity for and protective of the alienating parent, and anger and hurt toward the target parent. The confidences are shared in such a way as to flatter the child and appeal to his/her desire to be trusted and involved in adult matters.

10. Forcing child to reject the target parent: Alienating parents create situations in which the child actively rejects the target parent, such as calling the target parent to cancel upcoming parenting time or request that the target parent not attend an important school or athletic 
event. Further, once children have hurt a parent, the alienation will become entrenched as the child justifies his/her behavior by devaluing the target parent.

11. Asking the child to spy on the target parent: Once children betray a parent by spying on them, they will likely feel guilty and uncomfortable being around that parent, thus furthering the alienation.

12. Asking the child to keep secrets from the target parent: The alienating parent will ask or hint that certain information should be withheld from the target parent in order to protect the child's interests. Like spying, keeping secrets creates psychological distance between the target parent and the child.

13. Referring to the target parent by first name: Rather than saying "Mummy/Daddy" or "Your mummy/your daddy the alienating will use the first name of the target parent when talking about that parent to the child. This may result in the child referring to the target parent by first name as well. The message to the child is that the target parent is no longer someone who has a special bond with the child. By referring to the target parent by first name, the alienating parent is demoting to the level of a peer or neighbor.

14. Referring to a step-parent as "Mum" or "Dad" and encouraging child to the same: The alienating parent will refer to that parent as the mother/father to the child and create the expectation that the child will do so as well.

15. Withholding medical, academic, and other important information from target parent/keeping target parent's name off medical, academic, and other relevant documents: The target parent will be at a decided disadvantage in terms of accessing information, forging relationships, being contacted in emergencies, being invited to participate, being provided with changes in schedules/locations, and so forth. This marginalizes the target parent in the eyes of the child and important adults in his/her life. They also make it considerably more difficult for the target parent to be an active and involved parent.

16. Changing child's name to remove association with target parent: The target parent may feel that the name change represents a rejection of him/her and will experience hurt, sadness, and frustration.

17. Cultivating dependency/undermining the authority of the target parent: Alienating parents develope dependency in their children rather than help their children develop selfsufficiency, critical thinking, autonomy, and independence. At the same time, they will undermine the authority of the target parent in order to ensure that the child is loyal to only one parent (Baker, A. J. L. \& Darnell, D. 2006).

According to Baker and Darnell, each of the 17 strategies serves a number of functions:(a) to further the child's cohesion and alignment with the alienating parent; b) to create a psychological distance between the child and the targeted parent; c) to intensify the targeted parent'sanger and hurt over the child's behavior, and d) to incite conflict between the child and the targeted parent challenge or react to the child's behavior.

In his turn, Edward Kruk identifies the following forms of alienating parent behavior:

1. Seizing the child by force.

2. A belief in one's entitlement as the primary or sole parental figure in the child's life, and lack of validation or recognition of the salience of the other parent as a parent.

3. Insensitivity to and disregard for the impact of one's behavior on children; lack of regard for and attunement to children's needs. Willingness to engage in conflict in front of the children. Lack of emotional depth and emotional responsiveness in relationship with one's child. Parentification of the child.

4. Overt or covert obsession with the other parent, and with hurting the other parent, to the extent that the obsession prevails over one's parental responsibilities.

5. Willingness and enthusiasm to engage in adversarial combat, and skill in the adversarial arena.

6. Refusal to communicate, or engage in a negotiation process. 
7. Refusal to accept responsibility for one's own contribution to the problem situation or conflict.

8. Readiness to accuse the other party of wrongdoing.

9. Lack of guilt or remorse for one's behavior.

10. Exaggeration and dishonesty; an attitude of, "the end justifies the means."

11. Badmouthing of the other parent in front of the child, or avoiding any mention of the other parent in an attempt to erase that parent from the child's memory.

12. Monitoring and questioning the child in regard to the child's relationship with the other parent (Kruk, E., 2018).

First of all, according to targeted parents, compulsory seize of the child involves the refusal of the communication and illegal use of the legal system to disrupt parental involvement in the child's life, which is aimed at the complete alienation of the parent from the child's life. In fact, alienated parents define alienation as a forced physical separation between parent and child.

Thus, parental alienation as the first element in defining the form of cruelty to a child is related to the cruel and violent behavior of the parent-alienator. The second component of the definition focuses on the child's profoundly harmful effects. In the most serious cases, these consequences are profound. First, nurturing hatred for the other parent is tantamount to instilling self-hatred in the child. Self-hatred is a particularly worrying feature of aliented children and one of the most serious and widespread consequences of parental alienation. Children who adopt hatred of the aliented parent tend to believe that the aliented parent did not love or want them, and they feel great pain about being betrayed by the aliented parent. The hatred for them stems from the parent's feeling of dislike and separation from them, at the same time they refuse to mourn the loss of the parent or even talk about it.

Parental hatred is not the emotion that a child naturally has. In situations of alienation from parents, such hatred is constantly transferred to them. Parental hatred makes children hate themselves, which makes children feel helpless, hurt, unhappy, unwanted.

Second, numerous studies show that alienated children have serious mental and social disorders. These include impaired social and emotional development, lack of trust in relationships, social anxiety, and social isolation. These children have a bad relationship with both parents. As adults, they tend to establish partnerships, are more likely to be divorced, have children in unstable relationships, and are separated from their own children.

And of course, the biggest consequence that is known to all of us is the emergence of emotional or psychological deprivation. Closer to this notion is the definition of deprivation as "a biologically adequate but psychologically restricted environment." However, as a final definition, we can adopt the following definition: "Psychological deprivation is a psychological condition arising from situations in life where the subject is not given some opportunity to meet some of their basic (vital) psychological needs, even for a long period of time." (Langmejer J., Matejchek Z., 1984)

The notion of "deprivation" should be distinguished from the concept of "neglect", which may be said to be a consequence of the adverse external influence of upbringing.

A child with psychological deprivation often grows up in a hygienic environment, has primary care and supervision, but his intellectual, especially emotional, development is severely impaired.

The unsatisfactory relationship between parents and children can undoubtedly be the result of internal, psychological barriers.

\section{Conclusions}

Summarizing the above, we can come to the following conclusions:

- The parent is a source of satisfaction of important needs

- As a result of divorces, children become instruments in the hands of parents 
- Refusal of the child by one or another parent cannot be the result of the child's will (except in rare, exceptional cases)

- The child's degree of resistance to refusing to interact with one parent is directly proportional to the psychological pressure made by the other parent.

- Parental alienation can have serious consequences for the child's mental and why not physical development (up to serious illnesses)

- An effective plan should be developed and implemented for such cases, which should include both prevention, harm and consequences reduction.

\section{References}

AvdeevaN. (2005). Rol' materiiotca $v$ razvitiirebenka $v$ rannemdetstve // Doshkol'noevospitanie, pp. 117-122

Baker, A. J. L. \& Darnell, D. (2006). Behaviors and strategies employed in parental alienation. Journal of Divorce and Remarriage, 45, 97-124.

Baker, A. J. L. \&Eichler, A. (2016). The linkage between parental alienation behaviors and child alienation. Journal of Divorce and Remarriage, 57, 475-484.

Bernet, W., \& Baker, A. (2013) Parental alienation, DSM-5, and ICD-11: Response to critics. Journal of the American Academy of Psychiatry and the Law, 41: 98-104

Bowlby D J (1988). A Secure Base: Parent-Child Attachment and Healthy Human Development.Tavistock professional book. London: Routledge, pp. 18-57

Clawar, S. S., \&Rivlin, B. V. (2013). Children held hostage: Identifying brainwashed children, presenting a case, and crafting solutions. Chicago, IL: American Bar Association.

Gottlieb, L.J. (2012). The Parental Alienation Syndrome: A family therapy and collaborativesystem approach to amelioration, Springfield, IL: Charles C Thomas Publishers. p.52

Harman, J. J., Kruk, E., \& Hines, D. A. (2018). Parental alienating behaviors: An unacknowledged form of family violence. Psychological Bulletin, 144(12), 1275-1299:

Jejnsvort M. D. (1979). Detsko-materinskajaprivjazannost' // Amer. Psihol. asssociacija- t. 11. -pp. 67-104

Krajg G. (2000). Psihologija razvitija. SPb.: Piter, 992 p

Kruk, E. (2018). Parental Alienation as a Form of emotional Child abuse: Current State of Knoweledge and Future Directions for Research, Family Science Review, Volume 22, issue 4, p. 144:

Kruk, E. (2018). The perspectives and needs of parents experiencing severe parental alienation: qualitative study examining parent-child contact loss. Paper presented at the Conference of the International Association for Relationship Research, Fort Collins, CO, July,

Langmejer J., Matejchek Z. (1984) Psihicheskaja deprivacija v detskom vozraste

Smirnova E.O. (1995). Teorija privjazannosti: koncepcija i jeksperiment // Vopr. psihol. pp $134-150$

Titarenko V. Ya. (1987). Sem'yaiformirovanielichnosti. M.: Mysl'. 352 s.- Dumitrashku T.A. (1991) Vliyanie vnutrisemeynykhfaktorov na formirovanie individual' nosti / T.A. Dumitrashku // Voprosypsikhologii, no. 1: 135 p. 